\title{
Barriers to ICT Adoption in Construction Revisited
}

\author{
Žiga Turk
}

University of Ljubljana, Slovenia, ziga.turk@fgg.uni-lj.si

\begin{abstract}
The paper presents introduction to a study on the barriers to the implementation of information and communication technologies (ICT) in construction. In the study, we compared the ICT use in construction with some other industries - as reported in the literature and some industrial studies. We challenge the conventional wisdom that construction industry is not being rational in its choices to adopt (or not) various ICTs. We approached the issue from several methodological frameworks. In the paper we structure the reasons along the PESTEL framework. We examine each of the factors and suggest how they could be overcome. A survey has been designed and executed among the members of the Advisory Board of the EU Digiplace project. The results show that the industrial partners are less critical of the technology migration problems than researchers. The paper concludes that there is a need for a better way of deployment of and learning about new technologies that would benefit small and medium enterprises - the lag in productivity growth is largest there. This could be implemented in the form of industrial platforms in the context of the developments of the Industry 4.0.
\end{abstract}

(c) 2020 The Authors. Published by Budapest University of Technology and Economics \& Diamond Congress Ltd Peer-review under responsibility of the Scientific Committee of the Creative Construction Conference 2020.

Keywords: information and communication technology, technology adoption, construction platforms, construction industry

\section{Introduction}

Information and communication technologies (ICT) are one of the most rapidly developing fields of technology. They influence not only the closely related software and computing hardware industry but all sectors, including construction. One of the problems that the construction research community is facing is how closely it should follow these developments and which to augment for use in construction.

The construction industry too faces many challenges when making decisions on deployment and investments in ICT. Many (Brandon and Betts 1997, Turk 2000, Stouffs and Krishnamurti 2001, Amor at al. 2002, Sarshar, 2004, Flood, 2004, Yan, 2008, He, 2012, Chan, 2014, Mtya, 2019) have claimed that the penetration of modern ICT into the construction industry lags well behind the inventions of the research community and elaborated on the reasons for this.

While certainly valid and influential, what those reasons have in common is that they are looking for the causes outside of the construction information technology.

The hypothesis in this paper is that the construction sector is being rational about its adoption of ICT and that should we want to increase the use of ICT, a better delivery mechanism needs to be found. It could find an example in the delivery mechanisms for the general, popular information technologies, people, including construction professionals, use on a daily basis. 


\section{PESTEL analisys of the barriers}

A PESTEL analysis (Professional Academy, 2020) is an approach originally utilized by marketers to understand the macro-environmental variables that have an effect on acceptance of a product, an organization, a system. The result the examination is then utilized to recognize dangers and shortcomings which is utilized in a SWOT analysis.

The acronym PESTEL stands for the following facets of examination:

- P - Political

- E-Economic

- S-Social

- T-Technological

- E - Environmental

- L- Legal

While the PESTEL was initially conceived to assist in marketing it, provides a framework to analyze barriers between customers (such as the construction industry) and performers (providers of information technology and other advanced technologies).

\subsection{Political}

These are about how and to what degree a government mediates within the economy. This may incorporate - government arrangement, political soundness or flimsiness in abroad markets, outside exchange arrangement, assess policy, labor law, natural law, exchange limitations and so on. It is evident from the list over that political components regularly have an effect on associations and how they do commerce. Associations got to be able to reply to the current and expected future enactment and alter their showcasing arrangement appropriately.

We have been finding that in construction, policies are lacking on a project, company, national and EU level that would mandate or encourage the use of advanced ICT and make their use profitable.

\subsection{Economic}

Economic factors are about how a company does its business and how profits and other economic goals are affected. The factors include GDP growth, interest and exchange rates, inflation, disposable income of consumers and businesses etc. A distinction can be made into macro- and micro-economic factors. Macroeconomic ones are about the general economic climate in an economy. Micro-economic factors are about how customers need the products and services of the company.

We have been finding that in construction new ICTs are expensive, economic advantages not understood well enough; they are rather unfriendly, call for extensive and expensive training; low profit margins and tight deadlines discourage experimentation and novelties; near monopoly status of a few software companies.

\subsection{Social}

These factors represent the human and social characteristics, norms, customs and values of the people with which the business is involved with - including its own staff, partners and customers. These factors are believed (B2U, 2016) to be particularly important when targeting certain customers or constituencies. Additionally, these factors may include the attitudes of local workforce.

We have been finding that in construction there are some rigid and conservative practitioners, caution, unwillingness to learn, and widespread resistance to change that slow down the progress.

\subsection{Technological}

These factors are about technological innovations and how they affect the operations of the business and its industry. It refers to the level of innovation, technology incentives, automation, technological change 
research and development (R\&D) activity, and the amount of technological awareness that a market possesses. These factors may have an impact on decisions to pursue or not pursue certain business opportunities, enter or not enter certain projects and domains. Awareness of what is going on technologywise impacts medium to long term strategic decisions of businesses.

We have been finding that in construction technology is rather unfriendly, often lacking compatibility and interoperability. Standardization has not been fully achieved. But generally, it is seen less of a problem than other elements; OpenBIM in not fully realised, implemented and adopted.

\subsection{Environmental}

Environmental factors have been gaining attention rather recently with the increasing awareness of global warming and the need to address them - both in terms of mitigation as well as prevention. They are also important in the light of scarcity of raw materials, pollution, as well as carbon footprint targets set by governments. These factors include objective ecological and environmental aspects such as weather, climate as well as the attitudes of the people related to a business both as employees and customers. Therefore, many companies are increasingly involved in practices such as corporate social responsibility (CSR) and sustainability.

In construction we are finding that environmental policies (such a fighting climate change) are not a barrier but, on the contrary, a motivational element to include new technologies.

\subsection{Legal}

While there may be some overlap with the political factors, these factors include specific laws and regulations that impact that particular business. This is not at all limited to what is legal but is mostly about how regulations frame the business, its relations with customers and partners. Under this heading also standards, both the mandatory and the industry adopted ones, are included.

In construction we are finding that there are unsolved legal, copyright, and related IPR issues of working in a digital environment. Guidelines and regulation what the BIM centred process should look like are not generally available.

\section{Survey}

In the context of the Digiplace project a survey has been conducted among several companies across Europe. One of the questions was related to barriers of use of advanced digital tools such as BIM, 3D printing, thermal scanning, GIS, 3D modeling, etc.

When asked "do you use other more advanced digital tools" the number of replies maybe was 10, no 33 and yes 143 and in the questions of why don't you use more advanced digital tools, those that responded cited the answers as shown in the figure below:
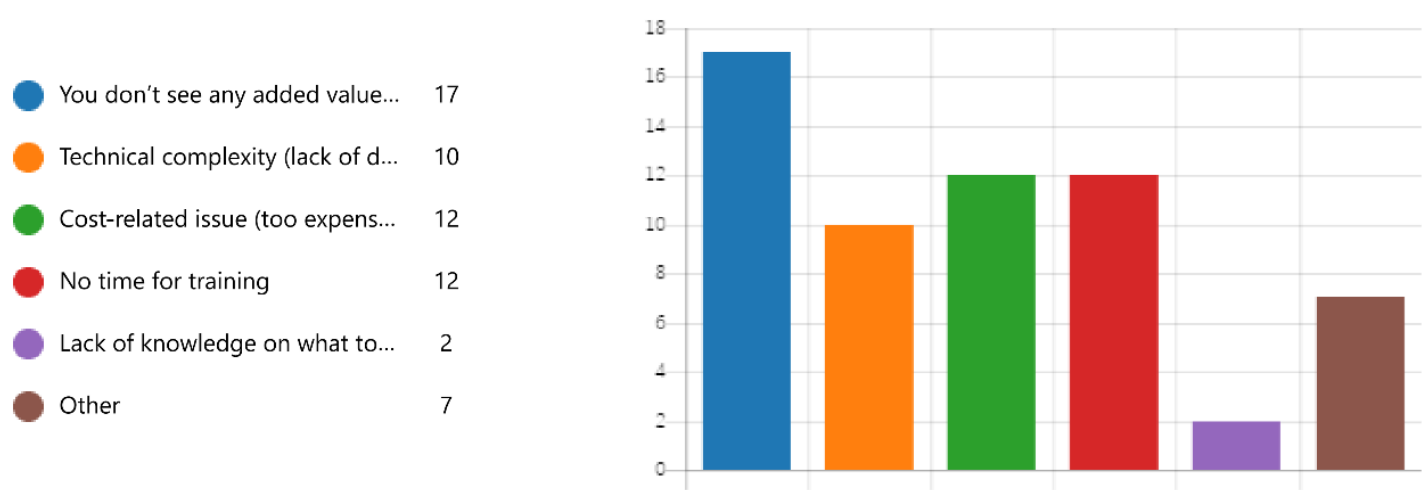

Figure 1. Why advanced ICT is not used more as per first Digiplace survey? 
Top reason as per surveyed is the lack of added value. At the other end of the spectrum seems to be access to knowledge. The respondents seem to be knowledgeable on one hand but lacking time to learn on the other.

\section{Conclusions and discussion}

Construction is lagging in productivity growth of the other sectors of the industry (McKinsey, 2017). The lag is particularly large in small and medium enterprises while the bigger companies are following or exceeding the trends of their countries. This calls for technologies and tools that help the SMEs. Platforms are such an approach.

Past empirical and theoretical studies as well as initial survey of the Digiplace project have identified several obstacles and barriers to a more intense use of ICT in construction. First and foremost, it must be remembered that the ICT will be used when economic and competitive benefits can be demonstrated. The efforts of policymakers, public procurement and professional associations could help in that.

Some of the efforts are already present in the EC (2019) report which recommends a rise in public awareness for digitalization is needed. "Besides resulting novel opportunities, this process also leads to an increased pressure for businesses" (EC, 2019).

There is a broad support for "a new and extended digital platform" (EC, 2019). Such a platform would address the issues of lack of knowledge as it would provide a context for a more friendly technology delivery tool and could as well provide best practices, guidelines and regulations how to organize for a BIM centered workflow. It is important not to forget that such a platform should "enable international usage, while being able to take local regulations into account" (EC, 2019).

\section{References}

[1] Amor R, Betts M, Coetzee G, Sexton M (2002) Information Technology for Construction: Recent Work and Future Directions, Electronic Journal of Information technology in Construction, Vol. 7, pg. 245-158. https://www.itcon.org/papers/itcon.paper.2002-16.pdf

[2] Brandon, P. and Betts, M. (1997) Veni, Vidi, Vici; in Brandon P and Betts M (editors), The Armathwaite Initiative, ISBN 1-900491-036, University of Salford, UK.

[3] Chan, C.T., 2014. Barriers of implementing BIM in construction industry from the designers' perspective: A Hong Kong experience. Journal of System and Management Sciences, 4(2), pp.24-40.

[4] EC (2019). Supporting digitalisation of the construction sector and SMEs, European Commission, ISBN 978-92-9202-626-4, https://doi.org/10.2826/422658

[5] Flood, I., Issa, R.R. and O'Brien, W., 2004. Barriers to the development, adoption, and implementation of information technologies: case studies from construction. In Towards a Vision for Information Technology in Civil Engineering (pp. 1-4). https://doi.org/10.1061/40704(2003)30

[6] He, Q. H., Qian, L. L., Duan, Y. F., \& Li, Y. K. (2012). Current situation and barriers of BIM implementation. Journal of Engineering Management, 1, 12-16.

[7] McKinsey (2017). REINVENTING CONSTRUCTION: A ROUTE TO HIGHER PRODUCTIVITY, McKinsey McKinsey Global Institute, February 2017, www.mckinsey.com/mgi

[8] Mtya, A. and Windapo, A., 2019. Drivers and Barriers to the Adoption of Building Information Modelling (BIM) By Construction Firms in South Africa. Innovative Production And Construction: Transforming Construction Through Emerging Technologies, p.215. https://doi.org/10.1142/9789813272491_0013

[9] Professional Academy (2020). " Marketing Theories - PESTEL Analysis ". Professionalacademy.Com. Accessed January 182020. https://www.professionalacademy.com/blogs-and-advice/marketing-theories---pestel-analysis.

[10] Sarshar M (2004). Construction Integration: Vision and Barriers, in Brandon, Li, Shaffii, Shen (eds.) Proceedings, Incite 2004 Conference, Construction Industry Development Board of Malaysia, 2004.

[11] Stouffs R, Krishnamurti R (2001) Standardization: A critical view, Coetzee G, Boshoff F (ed.); IT in construction in Africa 2001; Mpumalunga, 30 May - 1 June, South Africa; ISBN 0-7988-5531-2

[12] Turk, Ž. (2000) Construction IT: Definition, Framework and Research Issues, M. Fischiner (ed.) Faculty of Civil and Geodetic Engineering on the doorstep of the millennium : on the occasion of its 80th anniversary. ISBN 961-6167-33- 17-32.

[13] Yan, H., \& Demian, P. (2008). Benefits and barriers of building information modelling. IN: Ren, A., Ma, Z. and Lu, X. Proceedings of the 12th International Conference on Computing in Civil and Building Engineering (ICCCBE XII) \& 2008 International Conference on Information Technology in Construction (INCITE 2008), Beijing, China, 16th-18th October 2008. 